\title{
The comparative method for policy studies: the thorny aspects
}

\author{
Tatiana-Camelia, DOGARU (CRUCEANU),
} National University of Political Studies and Public Administration, Faculty of Public Administration, Romania, dogaru_tatiana@yahoo.com

\begin{abstract}
Over the past decades, the comparative method has attracted the attention of the theorists, and studies based on this approach have increased in applied policy research. In their daily and strategically policy decisions, the decision makers from local, regional and national levels use more and more the comparative research methods, especially due to interlinked relationship and the need for bench learning and benchmarking practices. The comparative method allows the actors to analyse other experiences, and thus to take decisions more efficient. This is a normal, an inevitable situation, when the unit of analysis is a country, a field of matters or a process where researchers compare cases from empirical or theoretical point of view. The purpose of this paper is to provide a critical view on the capacity of comparative method to foster knowledge in policy studies. The intention is to see and to explore the utility of comparative method for policy studies and policy analysis, since a new approach "evidence-based policymaking" arise, emphasising the importance of using evidence from other political and policy systems.
\end{abstract}

Keywords: comparative method, policy research, methodology in administrative science, policy system.

JEL Classification: N40, C83, D7.

\section{Introduction}

Since their beginning the policy studies are looking for a research paradigm, especially because they do not have a specific set of methodologies, but call upon a range of tools and methods from different sciences in order to achieve the analyse of the public policy problem and to find the best explanations for policy questions and alternatives. Traditional, the statistical 
methods have the greater influence among the policy-makers, but increasingly the complexity of the policy problem shift the view to new research methods. One of them being the comparative method.

Generally speaking, the comparative research methods provides a greater degree of knowledge on the administrative and political context, and on the features of public policy. In view of some scholars applying comparative method in policy research conducts to comparative public policy defined as (Heidenheimer et al., 1975) "cross-national study of how, why and to what effect government policies are developed".

Since 1971, Swanson (1971, p. 145) stated "thinking without comparison is unthinkable. And, in the absence of comparison, so is all scientific thought and scientific research".

\section{The particularity of policy studies}

Policy research differs from basic social research or technical research in a number of ways. Since 1984, Majchrzak outlined several differences which can be summing up, such as:

- policy research focuses on problems that have an important political impact, and it generally aims to increase the utility of the outcomes in order to get a greater understanding of the public polices problems, activities and impacts for resolving the social issues.

- the whole process of identifying policy issues, developing policy actions, and implementing policies is politically driven, so the research method needs to be available to take into account this dimension.

- issues on short term and highlighting the change represent, also core elements of the policy researches because the public policies have a big impacts over a considerable period of time. A key consideration in the design of policy studies is how time will be incorporated.

The particularity of policy studies come, also from the way in which policy is defined. The concept has been analysed by economists, sociologists, systems analysts, management scientist and political scientist, and the definitions vary even within the discipline. For instance, policy has been defined as "bundles of 
government decisions based on issues" (Smith, 1975) or "whatever governments chooses to do or not to do" (Dye, 1972: p. 2).

The new social phenomenon, namely globalisation, Europeanization, privatization, deregulation push the understanding of policy into a new paradigm called governance. Under this new approach, policy has diminished its characteristic as governmental activity and started to be described more as a process designed and applied in flexible structures involving social networks, governmental structures and markets, in other words, in collaborative governance context. In this context, of collaborative governance, the policymaking and the implementation are done in a more transparent and consultative processes, profoundly different by the traditional paradigm of policy and public administration. Under this movement, it can be said that governance is about policy stakeholders and their interdependent relations, as well as on the tools that support the coordination of policy processes in order to answer to the society' needs.

\section{The comparative method}

In the name of New Public Administration' movement, at the beginning of 1970s, a number of representative studies (Dror, 1968; Heclo, 1974; Heidenheimer et al., 1975; Ashford, 1978; Ashford et al., 1978) extended the scope of comparative research method to study the policy-making and its outcomes. The main goal of this development was the support the improvements in this field of research.

Suitable for both quantitative and qualitative methodologies and with a large-scale of applicability, the comparative method is applied in cross-cultural and cross-national context, in different policy fields (education, health, welfare so on). There is no single research style to reflect the comparative method, but rather more. A very well-known research style is the quasi-experimental design, especially used for assessing the policy initiatives from two or more areas or sectors, where ones received the policy initiative while the other no. From a broader perspective, the comparative method is considered a continuous approach, therefore sometimes the scholars refer to it in terms of "constant comparative method". In this sense, it can be outlined the Jupp' view (2006), which underlines different ways for using comparison, namely: 
- documents or content analysis,

- historical analysis (comparison of time periods) and,

- statistics analysis.

For understanding how policy is made, the comparative approach allows the process-tracing method (Blatter \& Haverland, 2014; Blatter \& Blume, 2008).

Schmitt (2012) stated that scholars prefer to use comparative methods for studying policy-making, because this type of research offers the possibility to know in a deep manner the causes, the institutional, economic and social factors and the networks of stakeholders that bring insights about the different types of policy decisions. Hence, the main value of the comparative research methods is their ability to provide a better understanding of contingent factors and processes of public policy through comparisons which lead to the knowledge and understanding of the similarities and differences among policies and their outcomes. This type of researches are very useful when one wants to study the convergence or divergence of policies. The units of analysis, such as local, national or regional level, and the period of time are methodological elements which can be the subjects of comparisons.

\section{Analysis: the power of comparative method in policy studies}

The comparative method facilitates the confrontation of different case studies, revealing concepts that can be used for theory building or for improving the theory. In the same time, it can be used for benchmarking, but the transposition of the best practice from one context to another is a sensitive work due to the different language and cultural context that can creates problems of comparability. Thus, one limit of comparative method in policy studies is to make for comparability. In terms of Przeworski and Teune (1970), the missing element of researches from comparative vein is known as the need for a "meta language". This core element can facilitate the evaluation of the statements regarding the comparability of phenomena across politico-administrative systems. Moreover, when one use this approach, a special attention need to be paid to the identification of the criteria that should be used to select the cases, other way finding cases first can compromise the findings. 
While the comparative method is useful to understand the processes and results, the main problem of it, still remains the generalization and extrapolation from convergent and divergent points among units of analysis, in case of public policies, these are represented by administrative and political structures, procedures and legal frameworks in different countries or over time. In this sense, Przeworski and Teune (in Kravchuk, 2008) identified several interrelated problems, namely ahistoricity, comparability, and reification. To be able to speak about ahistorical it is necessary to consider that the specific patterns and cultures of states have little importance for affecting the characteristics that policy processes, administrative practices, and implementation of policy can be in common.

Moreover, starting from the fact that context is essential, perhaps even crucial, scholars Przeworski and Teune (1970, p. 12) stated that the context in which the social reality is observed is fundamental, and "can never be explained by general law, such as statements". The above objection against generalization and extrapolation across disparate cases is not the only one, but on the contrary another common theoretical critique consist of uniqueness of politicoadministrative phenomena. Therefore, the explanatory power of comparative studies varies significantly across systems, and consequently different domestic features of the systems under analysis, like research questions, hypotheses to be misunderstood, ignored or even missed altogether. In words of Prezeworski and Teune (1970, p. 10) "a reification of concepts which projects the domestic context into an alien context" can be a major issue for all spatio-temporal studies.

Going further, it is important for notice that scholars have adopted two different conceptions on comparative policy analysis (Peters, Fontaine \& Mendez, 2018):

- firstly, can be noted the trend comprising comparative studies stressing the nature of policies themselves. From the perspective of these theoretical lens, the majority of comparative policy studies are based on a "small-N comparison method, rather than experimental and statistical and study case methods" (Lijphart, 1971). 
- secondly, other conceptions use comparative policy studies as a subset of comparative politics (Lodge, 2007; Caramani, 2014)., and stress the political roots of policy options.

Summing up, it is worthy to mention that the theorists of comparative policy analysis seek to design a framework for describing and explaining systematically the policies made by different governments, their content, outcomes and timing. However, there is difficult to conduct a comparative study on public policy, especially due to the ambiguity in the concept of policy and disagreement over what and how to compare.

Comparison is a method for the study of public policy, and there are significant efforts to compare policies across systems and countries.

\section{An example of comparative approach in policy}

In the view of the most policy studies, the policy process is defined as a rational process, starting from the identification of problem and agenda-setting to implementation and evaluation of the programme, where the last provides data for the next cycle of policy design.

Figure 1. Policy-making cycle

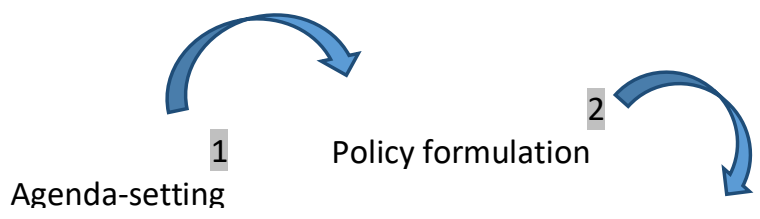

$$
\text { Decision-making }{ }^{3}
$$

6 Policy termination

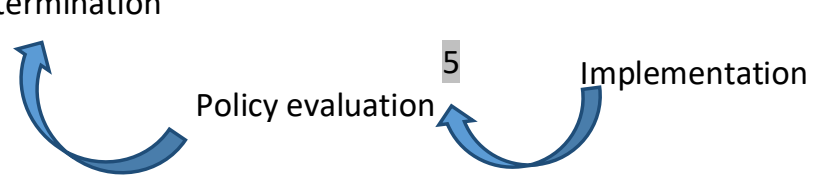

Source: author based on Jones' view

In practice however policy-making is a much more flexible process which is not conducted by rigid rules. Thus, in reality the policy process is more complicated and sometimes chaotic (EC, 2016). Furthermore, the reality of policy-making varies greatly from the classical policy model whichsays that policy 
cycle is a linear process, sequential and end-to-end process, and where policy makers have enough time conduct each stage and analyse the potential impacts for each policy options before proceeding to the next one. Nevertheless, in reality, there is an interdependent relationship between the policy stages, and sometimes they can be performed simultaneously or separately. In this context, although the policy process is closely linked to the administrative tradition of state, the public policy-making process has undergone profound transformation under globalization and Europeanization challenges. In this sense, the policy process of European Union Member States can represents a unit of comparative analysis.

For example, if we are looking from comparative perspective to Southern, Central and Eastern European countries, we can remark that policy-making has frequently a normative nature and end into a law, with a citizen participation underdeveloped. Also, a common pattern noticed is that the most EU countries have opened the policy arena for involving a number of stakeholders, but even then the policy can become a "bad policy" during implementing stage, especially due to the lack of stakeholders' engagement. In this case, there may be unexpected and unfortunately results and consequences. For more insights, the author makes reference to the EUPACK study which shows the following status for citizens' participation in policy-making:

Table 1. Degree of citizens' participation in policy-making

\begin{tabular}{lll}
\hline Strong & Medium & Weak \\
\hline Denmark, Malta, & Germany, France, Ireland, & Austria, Belgium, Bulgaria, \\
Netherlands, Sweden & Latvia, Luxembourg, Great & Cyprus, Czech Republic, \\
& Britain & Estonia, Spain, Finland, \\
& Croatia, Italy, Lithuania, \\
& Poland, Portugal, Romania, \\
& Slovenia, Slovakia, Greece, \\
& Hungary \\
\hline
\end{tabular}

Source: EUPACK in EU 2018

Also, the comparative research allow as to say that at EU Member States level there is no one policy source or the same one, contrariwise there are several sources, namely (EU, 2018):

- political promise made during election time,

- individual priorities of elected officials,

- obligations from EU legislation and international law, 
- public pressure,

- emerging crises,

- new approaches to old policy issues,

- think tanks and associations lobby activity,

- bureaucracy itself.

In this context, an important aspect of policy-making is the arena of policy advice because the variety of the actors involved and the extent of the arena can increase the likelihood of the new ideas to get into the attention of the government. According to (Pollitt \& Bouckaert, 2017), in most of the EU Member States the policy advice is taken from several sources: top civil servants (mandarins), cabinets (direct personal advisors to Ministers), or external experts such as consultants, academics, international organisations, think-tanks or business administration. Therefore, if we take a look on the governance index, it can be notice the following evolution:

Table 2. Evolution of governance index

\begin{tabular}{lccccccccccc}
\hline \multicolumn{1}{c}{ Country } & \multicolumn{4}{c}{ Executive capacity } & \multicolumn{5}{c}{ Executive accountability } \\
\hline year & 2014 & 2015 & 2016 & 2017 & 2018 & 2014 & 2015 & 2016 & 2017 & 2018 \\
Austria & 6.15 & 6.2 & 6.2 & 6.2 & 6.2 & 7.09 & 7.1 & 7.2 & 7.2 & 7.0 \\
Belgium & 5.7 & 5.7 & 5.6 & 5.6 & 5.4 & 6.9 & 7.0 & 7.2 & 7.2 & 7.2 \\
Bulgaria & 4.8 & 4.6 & 4.8 & 4.8 & 4.8 & 5.5 & 5.4 & 5.4 & 5.4 & 5.6 \\
Croatia & 4.6 & 4.5 & 4.6 & 4.4 & 4.4 & 5.1 & 5.1 & 5.2 & 5.3 & 5.1 \\
Cyprus & 3.1 & 3.7 & 3.7 & 4.0 & 4.0 & 4.9 & 4.9 & 5.0 & 5.0 & 4.9 \\
Czech & 5.1 & 5.3 & 5.3 & 5.4 & 5.4 & 6.8 & 6.9 & 6.8 & 6.8 & 6.6 \\
Republic & & & & & & & & & & \\
Denmark & 8.4 & 8.4 & 8.4 & 8.4 & 8.4 & 8.3 & 8.3 & 8.2 & 8.2 & 8.3 \\
Estonia & 6.4 & 6.3 & 6.2 & 6.2 & 6.4 & 6.5 & 6.4 & 6.4 & 6.4 & 6.4 \\
Finland & 8.6 & 8.6 & 8.5 & 8.4 & 8.3 & 8.4 & 8.3 & 8.3 & 8.3 & 8.2 \\
France & 6.6 & 5.9 & 6.2 & 6.3 & 7.0 & 5.4 & 5.4 & 5.5 & 5.8 & 5.6 \\
Germany & 6.9 & 6.9 & 6.8 & 6.9 & 7.0 & 7.6 & 7.6 & 7.4 & 7.3 & 7.2 \\
Greece & 4.3 & 4.3 & 4.0 & 4.4 & 4.7 & 5.4 & 5.7 & 5.6 & 5.7 & 6.0 \\
Hungary & 5.2 & 5.2 & 5.1 & 5.0 & 5.0 & 5.2 & 4.9 & 4.9 & 4.8 & 4.8 \\
Ireland & 6.4 & 6.7 & 6.7 & 6.7 & 6.7 & 6.6 & 6.7 & 6.7 & 6.5 & 6.6
\end{tabular}




\begin{tabular}{lllllllllll} 
Italy & 5.8 & 6.1 & 6.3 & 6.6 & 6.4 & 6.1 & 5.9 & 5.9 & 6.0 & 6.0 \\
Latvia & 6.31 & 7.3 & 7.3 & 7.3 & 7.4 & 7.4 & 5.2 & 5.2 & 5.2 & 5.2 \\
Lithuania & 7.1 & 7.2 & 7.2 & 7.2 & 7.1 & 5.9 & 5.8 & 5.8 & 5.9 & 5.7 \\
Luxembourg & 6.8 & 6.8 & 6.8 & 6.8 & 6.9 & 8.2 & 7.9 & 8.1 & 7.9 & 8.0 \\
Malta & 4.8 & 5.0 & 5.3 & 5.4 & 5.6 & 6.1 & 6.2 & 6.2 & 6.3 & 6.2 \\
Netherlands & 6.3 & 6.2 & 6.1 & 6.1 & 6.3 & 6.6 & 6.8 & 6.6 & 6.5 & 6.6 \\
Poland & 7.2 & 7.3 & 7.3 & 5.5 & 5.2 & 6.3 & 6.2 & 6.2 & 6.1 & 5.4 \\
Portugal & 6.1 & 5.8 & 5.8 & 6.2 & 6.1 & 5.3 & 5.4 & 5.3 & 5.3 & 5.4 \\
Romania & 4.4 & 4.4 & 4.5 & 4.8 & 4.3 & 4.7 & 4.6 & 4.7 & 4.9 & 5.0 \\
Slovakia & 5.4 & 5.4 & 5.3 & 5.1 & 5.0 & 5.5 & 5.5 & 5.4 & 5.4 & 5.4 \\
Slovenia & 4.4 & 4.6 & 4.7 & 4.7 & 4.7 & 6.4 & 6.2 & 6.2 & 6.1 & 6.1 \\
Spain & 6.3 & 6.5 & 6.4 & 6.4 & 6.4 & 6.3 & 6.3 & 6.5 & 6.4 & 6.3 \\
Sweden & 8.4 & 8.4 & 8.3 & 8.4 & 8.4 & 8.7 & 8.4 & 8.6 & 8.5 & 8.4 \\
United & 7.2 & 7.3 & 7.7 & 7.6 & 7.4 & 6.6 & 6.7 & 6.8 & 6.8 & 6.8 \\
Kingdom & & & & & & & & & & \\
\hline
\end{tabular}

\begin{tabular}{llllll}
\hline \multicolumn{1}{c}{ Country } & \multicolumn{5}{c}{ Governance } \\
\hline year & 2014 & 2015 & 2016 & 2017 & 2018 \\
Austria & 6.62 & 6.65 & 6.68 & 6.69 & 6.61 \\
Belgium & 6.29 & 6.35 & 6.43 & 6.39 & 6.31 \\
Bulgaria & 5.16 & 5.03 & 5.10 & 5.10 & 5.17 \\
Croatia & 4.86 & 4.83 & 4.89 & 4.84 & 4.75 \\
Cyprus & 3.98 & 4.29 & 4.32 & 4.51 & 4.47 \\
Czech & 5.97 & 6.08 & 6.09 & 6.09 & 6.04 \\
Republic & & & & & \\
Denmark & 8.34 & 8.38 & 8.31 & 8.34 & 8.36 \\
Estonia & 6.45 & 6.36 & 6.34 & 6.30 & 6.43 \\
Finland & 8.46 & 8.45 & 8.37 & 8.33 & 8.24 \\
France & 6.02 & 5.65 & 5.84 & 6.05 & 6.30 \\
Germany & 7.23 & 7.26 & 7.12 & 7.12 & 7.11 \\
Greece & 4.88 & 5.03 & 4.84 & 5.07 & 5.36
\end{tabular}




\begin{tabular}{llllll} 
Hungary & 5.20 & 5.02 & 4.96 & 4.89 & 4.90 \\
Ireland & 6.45 & 6.69 & 6.69 & 6.65 & 6.66 \\
Italy & 5.95 & 6.00 & 6.11 & 6.29 & 6.20 \\
Latvia & 5.2 & 6.22 & 6.24 & 6.24 & 6.29 \\
Lithuania & 6.50 & 6.53 & 6.49 & 6.53 & 6.44 \\
Luxembourg & 7.52 & 7.36 & 7.45 & 7.39 & 7.41 \\
Malta & 5.44 & 5.60 & 5.74 & 5.84 & 5.85 \\
Netherlands & 6.48 & 6.50 & 6.30 & 6.30 & 6.46 \\
Poland & 6.76 & 6.73 & 6.76 & 5.79 & 5.30 \\
Portugal & 5.67 & 5.59 & 5.53 & 5.75 & 5.71 \\
Romania & 4.55 & 4.49 & 4.61 & 4.86 & 4.64 \\
Slovakia & 5.46 & 5.41 & 5.34 & 5.26 & 5.23 \\
Slovenia & 5.38 & 5.37 & 5.45 & 5.41 & 5.40 \\
Spain & 6.32 & 6.39 & 6.44 & 6.37 & 6.35 \\
Sweden & 8.54 & 8.40 & 8.48 & 8.44 & 8.39 \\
United & 6.93 & 7.01 & 7.28 & 7.21 & 7.10 \\
Kingdom & & & & & \\
\hline
\end{tabular}

Source: author based on Sustainable Governance Indicators

The analysis of this index, from comparative perspective give a comprehensive perspective on government's capacity for steering and implementing policies, as well as on its capacity for institutional learning. These indicators permit a contextualized assessment that it is very important in relation to the reforms engaged by the most of countries for strengthening the policy capacity. Moreover, the value of this indicators is more important since the index is based on the 41 countries and use a scale from 1 to 10 for emphasising government's capacity to deliver sustainable policies.

In this sense, and having into account that the governance index does not regard the reform only economic point of view, the index is a very useful tool for a comparable analysis.

\section{Conclusions}


Majchrzak (1984) concluded that no comprehensive methodology for policy research exists, so researchers must know a variety of different methods in order to apply them to particular research questions. Since the environment is a core element of policy process and it is in a continuous changing, one can says in an extreme view that policy science will never be a precise science. However, the comparative research methods gives a tool, a framework for understanding and interpreting the relative cases, using substantive and theoretical indicators. So, although comparative approach is sometimes thought to be an arcane research exercise, it can provide useful insights for policymakers.

When researchers use the comparative methods to understand policy, there is a need for a better knowledge of the culture, history, administrative and political arrangements, and so forth of the subjects before beginning the analysis. Hence, the scholars who embrace the comparative approach are struggling to understand the domestic (indigenous) factors first.

In contrast toquantitative and experimental tools, the comparison method allow to bring the context more directly into a study. For policy scholars, the comparative method, provides more opportunities for a collective understanding of policy processLijphart (1971). The coherence of policy-making coordination also is strongly affected by key characteristics of the state system.

\section{References}

[1] Ashford, D. (ed.) (1978). Comparing Public Policies: New Concepts and Methods, California: Sage.

[2] Ashford, D., et. al. (eds.) (1978). Comparative Policy: A Cross-National Bibliography, California: Sage.

[3] Blatter, J. K. \& Blume, T. (2008). In Search of Co-variance, Causal Mechanisms or Congruence: Towards a Plural Understanding of Case Studies, Swiss Political Science Review, no.14, pp. 315-354.

[4] Blatter, J. K. \& Haverland, M. (2014). Case Studies and (Causal) Process-tracing, in I. Engeli and C. R. Allison, eds., Comparative Policy Studies: Conceptual and Methodological Challenges, Basingstoke: Macmillan.

[5] Caramani, D. (2014). Introduction to comparative politics, in D. Caramani (ed), Comparative Politics, Oxford: Oxford University Press.

[6] Dror, Y. (1968). Public Policymaking Reexamined, San Francisco: Chandler Publishing Co.

[7] Dye, T.R. (1972). Understanding Public Policy. Englewood Cliffs, NJ: Prentice-Hall.

[8] European Commission, DG Employment (2016), Quality of Public Administration: a toolbox for practitioners, pp.33-35. 
[9] European Union, 2018. A comparative overview of public administration characteristics and performance in the EU28, EU: Luxembourg.

[10] Heclo, H. (1974). Modern Social Politics in Britain and Sweden, New Haven, Connecticut; London: Yale University Press.

[11] Heidenheimer, A.J., et. al. (1975). Comparative Public Policy: The Politics of Social Choice in Europe and America, New York: St. Martins Press.

[12] Jupp, V. (2006). The Sage Dictionary of Social Research Methods. UK: Sage publications.

[13] Kravchuk, R. S. (2008). Comparative Research in Public Administration: A HistoricalInstitutionalist Perspective, in Miller, G \& Yang, K. (2008). Handbook of research methods in public administration, New York: CRC Press.

[14] Lijphart, A. (1971). Comparative Politics and the Comparative Method, American Political Science Review 65, pp. 682-693.

[15] Lodge, M. (2007). Comparative public policy, in F. Fischer, G. Miller and M. Sidney (Eds). Handbook of Public Policy Analysis: Theory, Politics and Methods, Boca Raton: CRC Press.

[16] Majchrzak, A. (1984). Methods for policy research. Newbury Park, CA: Sage.

[17] Peters, B. G., Fontaine, G. \& Mendez, J.-L. (2018) Substance and Methods in the Comparative Study of Policy Change, Journal of Comparative Policy Analysis: Research and Practice, 20:2, pp. 133-141.

[18] Pollitt, C. \& Bouckaert, G. (2017). Public Management Reform. A Comparative Analysis: A Comparative Analysis - Into the Age of Austerity, Oxford University Press.

[19] Przeworski, A. \& Teune, H. (1970). The Logic of Comparative Social Inquiry. Florida: Robert E.Kreiger Publishing Company.

[20] Schmitt, S. (2012).Comparative approaches to the study of public policymaking in Araral, E. et. al. Routledge Handbook of Public Policy, USA: Routledge.

[21] Smith, T.A. (1975). The Comparative Policy Process. Santa Barbara: ABC-Clio Ltd.

[22] Swanson, G. (1971). Frameworks for comparative research: Structural anthropology and the theory of action in Comparative Methods in Sociology: Essays on Trends and Applications, Berkeley: University of California Press. 